\title{
Anterior pituitary function after adrenalectomy in patients with Cushing's syndrome
}

\author{
M. Marazuela ${ }^{1}$, C. Cuerda, T. Lucas, A. Vicente, C. Blanco and J. Estrada \\ Service of Clinical Endocrinology, Clinica Puerta de Hierro, and ${ }^{1}$ Service of Endocrinology, Hospital de la \\ Princesa, Madrid, Spain
}

\begin{abstract}
Summary: We assessed anterior pituitary function in five patients with Cushing's syndrome before and after the removal of cortisol-secreting adrenal adenomas. Before surgery, all patients lacked response of growth hormone to hypoglycaemia, four had low responses of thyrotrophin to thyrotrophin releasing hormone, three had hypogonadism and two had low prolactin reserve. After successful removal of the adrenal adenoma, all patients developed postoperative hypoadrenocorticism and recovered all impaired anterior pituitary hormones within a period of 3 months. Our results point to a direct inhibiting action of glucocorticoids at the pituitary level as the explanation for the impaired anterior pituitary function. Moreover, direct gonadal suppression by glucococorticoids may be an additional mechanism of hypogonadism in some patients.
\end{abstract}

\section{Introduction}

Although several investigators have described abnormalities of anterior pituitary function in Cushing's syndrome, ${ }^{1-4}$ little information has been provided on the attainment of residual pituitary function after treatment of the disease. ${ }^{1,5,6}$ Moreover most studies have evaluated pituitary function after transsphenoidal surgery for Cushing's disease rather than after adrenal surgery. ${ }^{6}$ Although some authors have proposed a primary hypothalamic mechanism, ${ }^{7}$ most reports point to hypercortisolism as the cause of the abnormalities. ${ }^{1,5,6}$

In an attempt to clarify these results, we examined the anterior pituitary function, as well as thyroid and gonadal functions, before and after surgery in five patients with Cushing's syndrome secondary to adrenal adenoma, with special emphasis on the study of the gonadal axis.

\section{Patients and methods}

Anterior pituitary function was studied in five patients (four females and one male) with Cushing's syndrome prior to and after the removal of an adrenal adenoma. Ages ranged from 27 to 53 years with a mean of $40 \pm 9$. Diagnosis was reached on the basis of clinical findings and routine laboratory tests, as well as abdominal computed tomography. Basal levels of 24-hour urinary free cortisol (UFC) ranged from 130 to $700 \mu \mathrm{g} /$ day

Correspondence: M. Marazuela, M.D., Ph.D., Alfonso Rodríguez Castelao, 20, 28035 Madrid, Spain.

Accepted: 11 January 1993 (mean \pm SD: $346 \pm 203 \mu \mathrm{g} /$ day). After surgical adrenalectomy, all patients had a clinical remission and developed postoperative hypoadrenocorticism. Pituitary, thyroid and gonadal functions were assessed prior to and $3 \pm 1$ months after adrenalectomy.

We studied the responsiveness of anterior pituitary gland to simultaneous stimuli with insulin $(0.2 \mathrm{U} / \mathrm{kg})$, thyrotrophin releasing hormone (TRH) $(200 \mu \mathrm{g})$ and gonadotrophin-releasing hormone (GnRH) $(100 \mu \mathrm{g})$. The hypoglycaemic stimulus was considered adequate if the plasma glucose level fell below $2.2 \mathrm{mmol} / 1$ and this was achieved in all cases. Normal responses were considered to be a serum growth hormone (GH) $>7 \mathrm{ng} / \mathrm{ml}$, an increase in thyroid stimulating hormone (TSH) of 5-25 U/ml, a 3-5-fold increase in prolactin (PRL), a three-fold rise in luteinizing hormone (LH) and a $1 / 2$ to two-fold rise in follicle-stimulating hormone (FSH). Hyperresponsiveness was considered when the increments were more than 5-fold and 10-fold in FSH and LH, respectively. Basal levels of serum total thyroxine (T4), total triiodothyronine (T3), oestradiol (E2), progesterone (P) and total testosterone (TE) were measured in all cases. The free T4-index (FT4I) was calculated on the basis of the RT3 uptake.

\section{Results}

The results of the anterior pituitary, thyroid and gonadal function prior to and after surgery are summarized in Table I. Preoperatively, GH did not 
Table I Pituitary function before and after adrenalectomy

\begin{tabular}{|c|c|c|c|c|c|c|c|c|c|c|}
\hline \multirow[b]{2}{*}{ Sex/Age } & \multicolumn{2}{|c|}{$\begin{array}{c}\text { Patient } 1 \\
\text { F/27 }\end{array}$} & \multicolumn{2}{|c|}{$\begin{array}{c}\text { Patient } 2 \\
F / 34\end{array}$} & \multicolumn{2}{|c|}{$\begin{array}{c}\text { Patient } 3 \\
M / 46\end{array}$} & \multicolumn{2}{|c|}{$\begin{array}{l}\text { Patient } 4 \\
\text { F/42 }\end{array}$} & \multicolumn{2}{|c|}{$\begin{array}{c}\text { Patient } 5 \\
F / 53\end{array}$} \\
\hline & Preop. & Postop. & Preop. & Postop. & Preop. & Postop. & Preop. & Postop. & Preop. & Postop \\
\hline $\begin{array}{l}\text { UFC ( } \mu \mathrm{g} / 24 \text { hours }) \\
\text { GH (ng/ml) }\end{array}$ & 525 & 8 & 130 & 6 & 700 & 9 & 468 & $<5$ & 540 & 7 \\
\hline Basal & 0.2 & 1.8 & 1.6 & 0.5 & 0.2 & 3.3 & 0.2 & 0.3 & 0.2 & 0.3 \\
\hline Peak & 0.2 & 14.5 & 6.3 & 26.0 & 0.4 & 20.0 & 0.7 & 15.8 & 2.2 & 7.9 \\
\hline PRL (ng/ml) & & & & & & & & & & \\
\hline Basal & 4.5 & 3.6 & 6.3 & 7.2 & 3.7 & 2.4 & 2.8 & & 7.2 & 5.6 \\
\hline Peak & 6.0 & 19.0 & 9.0 & 24.5 & 21.8 & 15.0 & 51.6 & & 51.0 & 43.7 \\
\hline $\mathrm{TSH}(\mu \mathrm{U} / \mathrm{ml})$ & & & & & & & & & & \\
\hline Basal & 3.3 & 4.8 & 2.3 & 2.7 & 1.0 & 3.0 & 0.4 & 0.9 & 0.8 & 1.0 \\
\hline Peak & 5.1 & 15.0 & 9.8 & 5.3 & 2.0 & 10.5 & 2.2 & 7.8 & 3.3 & 4.2 \\
\hline LH $(\mathrm{mU} / \mathrm{ml})$ & & & & & & & & & & \\
\hline Basal & 2.0 & 3.5 & 7.3 & 19.8 & 2.4 & 5.8 & 1.3 & 50.9 & 12.0 & 44.0 \\
\hline Peak & 2.1 & 22.5 & 40.5 & 88.0 & 17.5 & 26.0 & 37.0 & 373.0 & 85.0 & 102.0 \\
\hline FSH $(\mathrm{mU} / \mathrm{ml})$ & & & & & & & & & & \\
\hline Basal & 2.0 & 5.5 & 4.4 & 8.6 & 2.2 & 2.3 & 2.8 & 41.3 & 29.0 & 91.2 \\
\hline Peak & 2.9 & 10.1 & 6.7 & 12.8 & 10.2 & 6.4 & 10.7 & 104.0 & 81.0 & 89.0 \\
\hline $\mathrm{T} 4(\mu \mathrm{g} / \mathrm{dl})$ & 4.1 & 9.3 & 6.8 & 8.9 & 6.1 & 7.2 & 7.7 & 9.1 & ${ }^{*} 1.02$ & ${ }^{*} 1.4$ \\
\hline T3 (ng/ml) & 0.3 & 1.7 & 0.6 & 1.3 & 0.6 & 1.6 & 0.8 & 1.2 & 0.7 & 1.5 \\
\hline $\mathrm{E} 2(\mathrm{pg} / \mathrm{ml})$ & 108.0 & 0.25 & 115.0 & 102.0 & - & - & 108.0 & 120.0 & 2.9 & $<$ \\
\hline $\mathrm{P}(\mathrm{ng} / \mathrm{ml})$ & 0.3 & 4.0 & 7.0 & 6.7 & - & - & 0.26 & 6.0 & 0.1 & 0.1 \\
\hline TE $(\mathrm{ng} / \mathrm{ml})$ & - & - & - & - & 1.6 & 6.3 & - & - & - & - \\
\hline
\end{tabular}

$\mathrm{UFC}=$ urinary free cortisol; PRL $=$ prolactin; ${ }^{*} \mathrm{FT} 4$ (free thyroxine) $(\mathrm{ng} / \mathrm{dl})$.

respond to hypoglycaemia in all cases. In the assessment of thyroid function, only one of our patients (patient 1) had a low T4 level with a normal FT4I. Total T3 levels were low in all cases (median \pm SD: $0.6 \pm 0.2$ ). The TSH response to TRH was low in four cases (patients 1, 3, 4 and 5) $(80 \%)$. The adult male (patient 3 ) was impotent and had a low testosterone level, with a normal LH response to $\mathrm{GnRH}$ and hyperresponsiveness of FSH to GnRH. Among the females, patient 2 had cyclic menses; patients 1 and 4 complained of amenorrhoea and had diminished and supranormal LH and FSH responses to GnRH, respectively; and patient 5 was postmenopausal. Basal PRL levels were normal in all patients, and failed to respond to TRH in two (patients 1 and 2).

After successful adrenalectomy, recovery of $\mathrm{GH}$, TSH, PRL, FSH and LH responses to hypoglycaemia, TRH and GnRH were documented in all cases with preoperative deficit (Figure 1). Basal levels of T4, T3, E2, progesterone and testosterone were also normalized in all patients with subnormal preoperative levels (Table I). The premenopausal and perimenopausal women regained normal cycles and the male patient recovered normal sexual function.

\section{Discussion}

There are conflicting reports about the effect of glucocorticoids on anterior pituitary hormones. ${ }^{1-6}$
Although the suppression of TSH and GH has been widely recognized, it is not clear whethe secretion of other pituitary hormones is alsङ5. affected. ${ }^{1-6}$

In our study, diminished or absent $\mathrm{GH}$ response to hypoglycaemia was found in all patients prior to adenalectomy, with recovery of normal function following clinical remission. Although suppression of the response of $\mathrm{GH}$ to hypoglycaemia has been documented previously in patients with Cushing's syndrome secondary to pituitary adenomas, ${ }^{1,5,7,8}$ it has seldom been reported in patients with adrenal adenoma or carcinoma. ${ }^{2,6,9}$ In addition, GH suppression has been found in normal subjects receiving long-term high-dose glucocorticoid therapy. ${ }^{10}$ Recovery of GH responsiveness after clinical remission has been reported in Cushing's disease ${ }^{1}$ as well as in one patient with Cushing's syndrome secondary to adrenal adenoma. ${ }^{6}$ Although a primary hypothalamic or central nervous system abnormality was postulated as the cause of faulty GH regulation in Cushing's disease, ${ }^{7}$ recent reports, including our results, point to hypercortisolaemia as the mechanism behind impaired GH secretion in Cushing's syndrome. ${ }^{1,5,8}$

Decreased responsiveness of plasma TSH to TRH was found in four of our five patients, with recovery in all cases after adrenalectomy. Previous reports have documented subnormal TSH responses to TRH in Cushing's syndrome as being either of pituitary or adrenal origin., 3,11-13 Although preliminary reports found no suppres- 

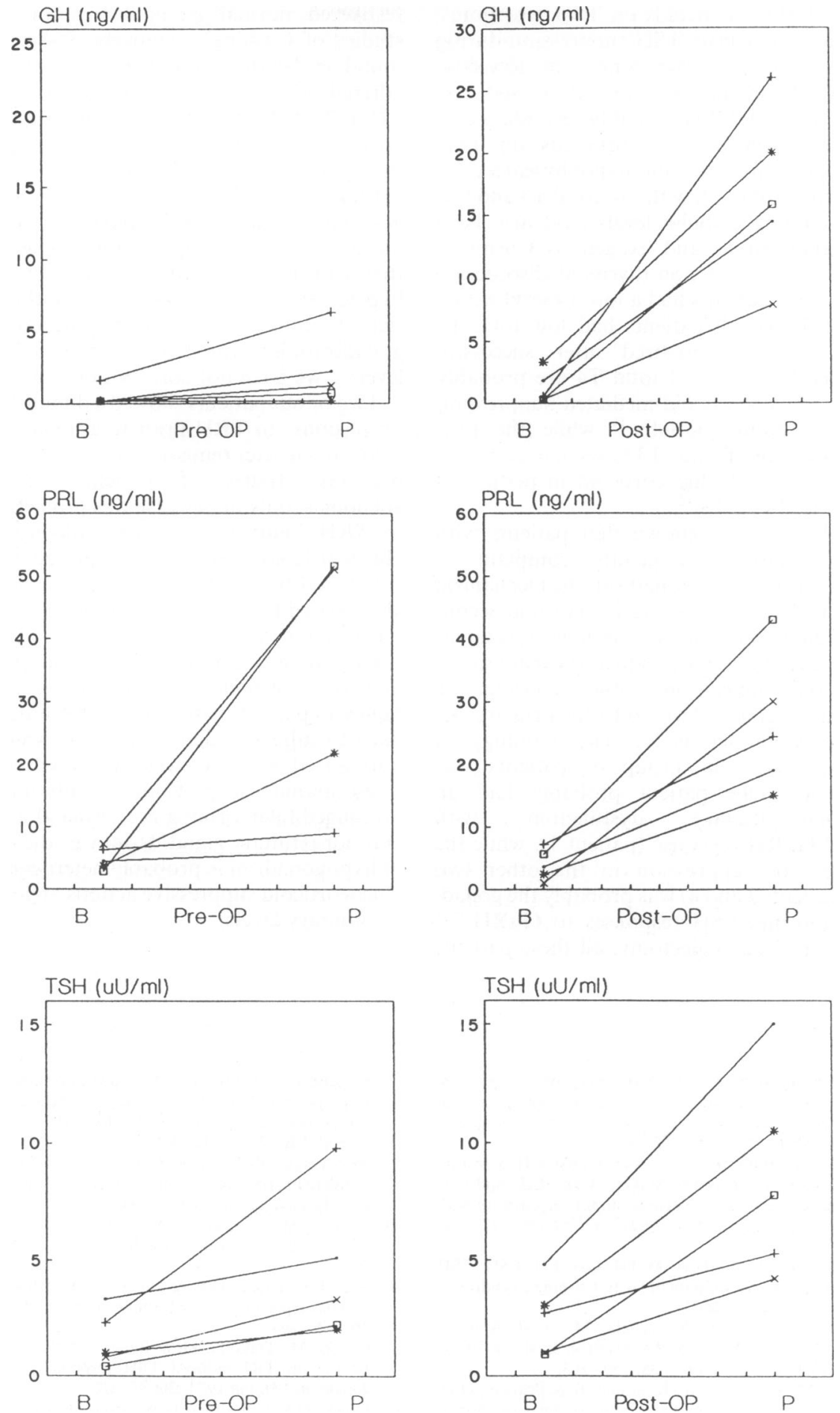

Figure 1 Plasma GH, PRL and TSH responses to insulin-induced hypoglycaemia and TRH before and after adrenalectomy. 
sive effect of glucocorticoids on TSH secretion, ${ }^{14}$ recent data demonstrate TSH suppression during short-term high-dose and long-term low-dose glucocorticoids treatment. ${ }^{11}$ The decreased response to TSH to TRH is probably secondary to a suppressive action of glucocorticoids on TSH release at the pituitary or suprahypophyseal level. ${ }^{11}$ Low to normal total T4, with low total T3 and low thyroxine binding globulin levels have also been found in endogenous and exogenous Cushing's syndrome, as in other non-thyroidal disorders. ${ }^{12}$ Only one of our patients had a low T4 level with a normal FT4I, but all patients had low total T3 levels that were normalized after successful surgery. The low levels of total T4 are probably related to a glucocorticoid-mediated suppression of thyroid binding globulin," while the pronounced lowering of total T3 is secondary to the suppressive effect of glucocorticoid in peripheral conversion of $\mathrm{T} 4$ to $\mathrm{T} 3 .^{12}$

Although it is well known that patients with Cushing's syndrome frequently complain of oligomenorrhea or hypogonadism, the mechanism of hypogonadism in Cushing's syndrome secondary to adrenal adenoma remains unclear; whereas some authors point to the gonad as the main site of glucocorticoid suppression, ${ }^{15}$ others consider the hypothalamo-pituitary level to be the primary site of glucocorticoid action. ${ }^{16-18}$ The aetiology of hypogonadism in our group of patients was heterogeneous. One patient probably had an hypothalamic-pituitary dysfunction with diminished GnRH response (patient 1), while the primary site of suppression in the other two patients (patients 3 and 4) was probably the gonad, with supranormal FSH responses to GnRH. ${ }^{15,16}$ After successful adrenalectomy, all these patients recovered normal gonadal function. In recent studies of Cushing's syndrome, ${ }^{15}$ the gonad was found to be the primary site of suppression in adrenal adenomas with normal or supranormal LH and FSH responses, while in pituitary microadenomas, the defect was located at the pituitary or the hypothalamic level. Our data suggest that in Cushing's syndrome secondary to adrenal adenoma there are both hypothalamo-pituitary and gonadal sites of suppression by glucocorticoids that can be successfully treated by correcting hypercorticism. Although some authors suggest that the inhibitory action of glucocorticoids on gonadotrophin synthesis or release is related to GC levels, ${ }^{18}$ we have not corroborated these findings.

Two or our patients showed a diminished prolactin response to TRH prior to adrenalectomy, but recovered it after remission of hypercortisolism. In previous studies of patients with adrenal adenomas, only in one case was prolactin response to TRH blunted. ${ }^{3,6,17}$ Pharmacological doses of glucocorticoids can suppress prolactin secretion stimulated by TRH. ${ }^{19,20}$ This suppression is probably related to a direct effect of glucocorticoids on the anterior pituitary gland.

Our data demonstrate the suppression of numerous responses of anterior pituitary hormones in patients with Cushing's syndrome secondary to adrenal adenoma, all of which becamee normalized after recovery from adrenalectomy These findings suggest direct inhibiting action of prolonged high serum glucocorticoid levels on the anterior pituitary gland. However, the mechanism of hypogonadism is probably heterogeneous, with glucocorticoid suppressive actions at gonadal and/ or pituitary levels.

\section{References}

1. Kuwayama, A., Kageyama, N., Nakane, T., Watanabe, M.\& Kanie, N. Anterior pituitary function after transsphenoidal selective adenectomy in patients with Cushing's disease. $J$ Clin Endocrinol Metab 1981, 53: 165-173.

2. Demura, R., Demura, H., Nunokawa, T., Baba, H. \& Miura, K. Responses of plasma ACTH, GH, LH and 11hydroxycorticosteroids to various stimuli in patients with Cushing's syndrome. J Clin Endocrinol Metab 1972, 34: $852-859$

3. Hashimoto, K. The pituitary ACTH, GH, LH, FSH, TSH and prolactin reserves in patients with Cushing's syndrome. Endocrinol Jpn 1975, 22: 67-77.

4. Cuerda, C., Estrada, J., Marazuela, M. et al. Anterior pituitary function in Cushing's syndrome: study of 36 patients. Endocrinol Jpn 1991, 38: 559-563.

5. Schnall, A.M., Brodkey, J.S., Kaufman, B. \& Pearson, O.H. Pituitary function after removal of pituitary microadenomas in Cushing's disease. $J$ Clin Endocrinol Metab 1978, 47, 410-417

6. Watanabe, K., Adachi, A. \& Nakamura, R. Reversible panhypopituitarism due to Cushing's syndrome. Arch Intern Med 1988, 148: 1358-1360.

7. Kreiger, D.T. \& Glick, S.M. Growth hormone and cortiso responsiveness in Cushing's syndrome. Relation to a possible central nervous system etiology. Am J Med 1972, 52: 25-40.

8. Tyrrell, J.B., Wiener-Kronish, J., Lorenzi, M., Brooks, R.M. \& Forsham, P.H. Cushing's disease: growth hormone response to hypoglycemia after correction of hypercortisolism. $J$ Clin Endocrinol Metab 1977, 44: 218-221.

9. Hartog, M., Gaafar, M.A. \& Fraser, R. Effect of corticosteroids on serum growth hormone. Lancet 1964, 2: 376-378.

10. Stiel, J.N., Island, D.P. \& Liddale, G.W. Effect of glucocorticoids on plasma growth hormone in man. Metabolism 1970 19: $158-164$.

11. Otsuki, M., Dakoda, M. \& Baba, S. Influence of glucocorticoids on TRF-induced TSH response in man. $J$ Clin Endocrinol Metab 1973, 36: 95-102.

12. Duick, D.S. \& Wahner, H.W. Thyroid axis in patients with Cushing's syndrome. Arch Intern Med 1979, 139: 767-772.

13. Inada, M., Kurata, Y., Hishikawa, M. et al. Cushing's syndrome associated with corticogenic hypothyroidism: a case study. Endocrinol Jpn 1971, 18: 101-108. 
14. Woolf, P.D., González-Barcena, D., Schalch, D.S. et al. Lack of effect of steroids on thyrotropin-releasing hormone (TRH)-mediated thyrotropin (TSH) release in man. Neuroendocrinology 1974, 13: 56-62.

15. Odagiri, E., Yamanaka, Y., Ishiwatari, N. et al. Studies on pituitary-gonadal function in patients with Cushing's syndrome. Endocrinol Jpn 1988, 35: 421-427.

16. Boccuzzi, G., Angeli, A., Bisbocci, D., Fonzo, D., Gaidano, G.P. \& Ceresa, F. Effect of synthetic luteinizing hormone releasing hormone (LHRH) on the release of gonadotropins in Cushing's disease. J Clin Endocrinol Metab 1975, 40: 892-895.

17. Luton, J.P., Thieblot, P., Valcke, J.C. Mahoudeau, J.A. \& Bricaire, H. Reversible gonadotropin deficiency in male Cushing's disease. J Clin Endocrinol Metab 1976, 45: 488-495.
18. White, M.C., Sanderson, J., Mashiter, K. et al. Gonadotropin levels in women with Cushing's syndrome before and after treatment. Clin Endocrinol 1981, 14: 23-29.

19. Sowers, J.R., Carlson, H.E., Brantbar, N. \& Hershman, J.M. Effect of dexamethasone on prolactin and TSH responses to TRH and metoclopramide in man. J Clin Endocrinol Metab 1977, 44: 237-241.

20. Kasperlick-Zarluska, A.A. \& Jeske, W. Serum prolactin responses to metoclopramide in Cushing's syndrome and Nelson's syndrome. Acta Endocrinol 1980, 93: 351-355. 